\title{
Research on Construction of Smart Tourism Perception System and Management Platform
}

\author{
Ning Wang ${ }^{1, a}$ \\ ${ }^{1}$ School of Foreign Languages\&International Business, Guangdong Mechanical\&Electrical College, \\ Guangzhou 510515, China \\ agdjdwn@qq.com
}

Keywords: Smart Tourism, Perception System, Management Platform.

\begin{abstract}
Smart tourism is a new concept focus on the tourism experience promotion. It is necessary to improve tourist experience using smart technologies, so that more efficient and appropriate measures can be taken and make a contribution to tourism experience promotion. In this paper, smarter tourism comes to be known with the deepening of the influence of information technology. In order to realize the intensification, intellectualization and unionization of tourism management, a smarter tourism perception system must be constructed on the base of cloud computing and the Internet of things so that standard information service is available to tourists, businesses and governments via its safe and online communicative functions. Smarter tourism perception system can connect travel attractions, hotels, transportation and other facilities tourist destinations of things completely to the Internet system and integration, data integration as the core database of tourism resources, which provide a more convenient means of destination tourism management and services.
\end{abstract}

\section{Theoretical Introduction of Smart Tourism}

The concept originated in the Smart tourism "Smarter Planet" is intelligent travel management platform, the use of tourism resources in the country, with the help of cloud computing and networking technology, tourism intensive, intelligent, unified management, improve national decentralized decision-making ability of the management of tourism resources, expanding service sector involved in the tourism industry, tourism-oriented, driven "travel, accommodation, food, shopping and entertainment," the development of related industries linkage type; using networking technology, laying multiple types of sensing devices in various types of tourism resources, tourism resources for the perception ID, property, status, location and so on.

All kinds of information, the formation of nerve endings smart tourism perception system; using the most advanced self-organizing wireless sensor network technology, combined with the Internet, for all types of sensing or control information transfer form successor smart tourism perception system / efferent network; combined with GIS technology, information technology and business intelligence resource integration technology, integration of various sensory information, data analysis and other processing re-use process, the formation of the brain smart tourism perception system. Cloud computing refers to the delivery of services and usage patterns, and network refers to the demand, and scalable way to get needed services [1].

The perceptual system can provide visitors with dining and entertainment consumer guide, remote resource reservation, since navigation, self-guided tours, electronic tickets, instant push service information and other intellectual tourism services; provide services for tourism enterprise resource management, tourist traffic control, vehicle scheduling, remote monitoring, automatic toll collection and other intelligence operations management services; government management services provide a variety of environmental monitoring, traffic management, resource scheduling, emergency treatment for the management department. 


\section{Functions of Smart Tourism}

Smart travel using cloud computing, networking and other new technologies, the Internet / mobile Internet, with the portable terminal access equipment, active perception of tourism resources, economic, tourist and other activities and the timely release of information, tourist destination and the Internet of Things completely connected systems and integration, data integration is the core database of tourism resources, through a more convenient means provide smart destination tourism management and services [2]. Fig.1 shows the functions of smart tourism.

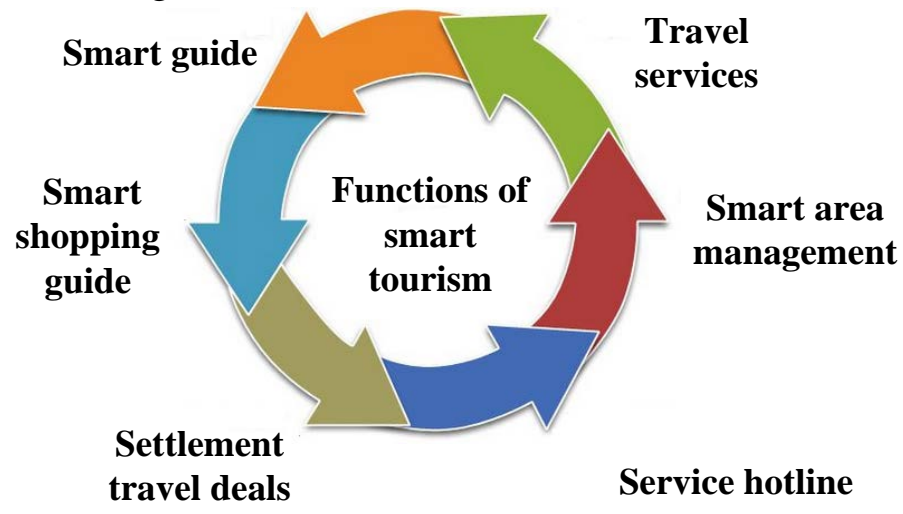

Fig. 1.The functions of smart tourism

Smart guides include: (1) a digital map system. Transportation, yellow pages, search, and so vast amounts of information covered on the map, and with a variety of functional interface. (2) The real-time information systems. The whole system of real-time dynamic can publish information, including weather, the flow of people, traffic, real-time promotions. (3) Tourist information systems, including the mass of tourist attractions, basic information and extended information sites. Smart shopping guide include: travel services perceived push system. The system uses networking technology to automatically promote catering to tourists, merchandise, entertainment and accommodation, information recorded by the service providers who own resources and real-time updates settlement travel deals. Settlement platform for online payments, card payments and other forms of providing transaction settlement services for travel services businesses, including corporate travel services for tourists B2C transaction payments, travel services companies B2 B deal with each other tourism services between business and IT services companies.

Service hotline provides combined business systems, call center systems, portals system for all travel services business platform hotline services, improve business travel e-commerce enterprises, standardize business processes and achieve booking hotels, air tickets, telephone inquiries attractions telephone, scenic activities, phone messages, suggestions and other business functions, providing customers with a full range of travel services. Smart area management include: scenic fare collection systems, namely computer as the core, network support, automatic access gates to the terminal, on the ticket, the ticket process of implementing electronic, automated, integrated management of networked computers. The terminal equipment as a tool for handling customer complaints and found even less scenic obstacles, from a macro perspective of a reasonable allocation of the advantages of tourism resources, from needs, improve intelligence travel business travel services [3].

\section{Construction of Perception System and Management Platform}

Smart tour operators and support platform, namely smart tourism management platform that can be dynamically scalable terminal to access a variety of applications and sensor nodes, the integration of a variety of service systems, and provide tourist attractions marketing smart, smart guides, smart shopping guide, transaction settlement, tourist attractions intelligence management, tourist attractions and other basic information resource management application services, as well as other industries, and tourism-related value-added type of application services, while providing a platform to support open business for other tourism enterprises [4]. 
The architecture is mainly involved in the overall perception layer, the cloud platform for building three parts layer, application service layer, by laying the tourist attractions in many types of sensing devices, the use of self-organizing wireless sensor network technology, combined with the Internet, with cloud platform, passing all kinds of perception or control information, and ultimately provide the basis for application services for tourist attractions, value-added application services and the openness of the class of business. Fig.2 shows the construction of perception system and management platform.

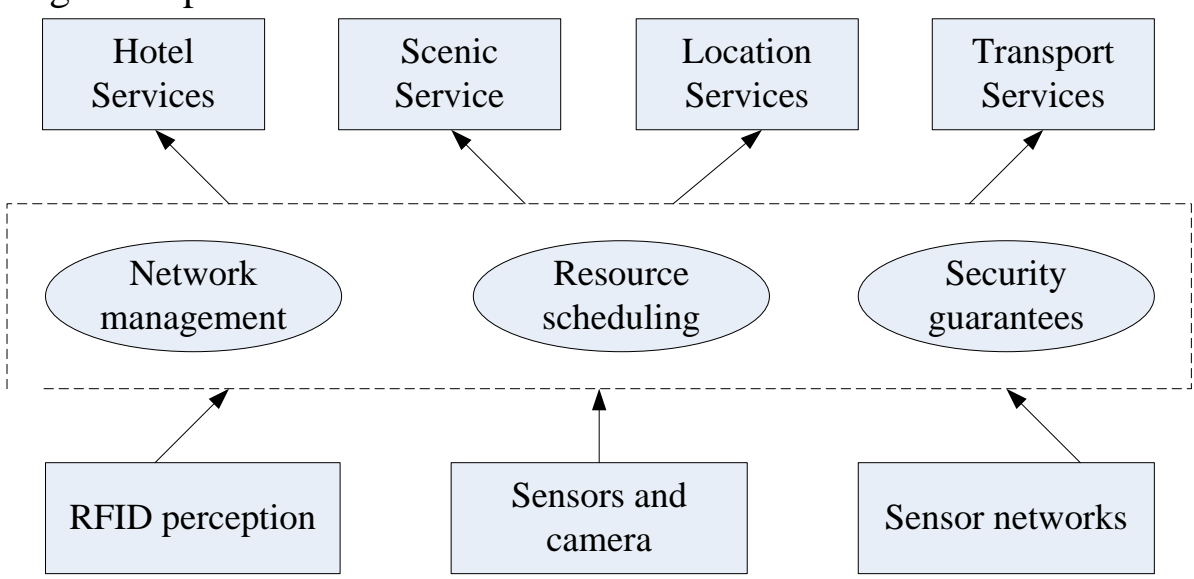

Fig. 2.The construction of perception system and management platform

Overall perception using a variety of sensor technology, combined with the specific application needs of different tourist attractions, a variety of sensor nodes deployed to the capillary microcirculation network management platform for building tourism smart dimensional perception system. From choosing travel destinations to travel, as well as by the accommodation, food, shopping and even entertainment and other sectors, based on geographic information through networking technology to the Internet as the basis, the use of sensors, RFID, Zig-bee, Bluetooth and sensor networks, to achieve a comprehensive perception.

\section{Key technologies}

Excellent tourism can achieve transformation must rely on the smart of the new technological revolution, in which networking technology, cloud technology, sensor technology, RF technology, network technology, intelligent information processing technology, the most important calculations. These techniques become an excellent tourist city smart transformation vector, urban operations and management tools.

Things sensing technology is through information sensing devices, according to the agreed protocol, to any items connected to the Internet, information exchange and communication in order to achieve intelligent identification, positioning, tracking, monitoring and management of a network. From a technical point of view, things are sensor networks. Sensing technology is about to obtain information from the source and nature of processing (transformation) and the identification of a multidisciplinary modern science and engineering, which involves sensors, planning and design of information processing and recognition, development system construction, testing, application and evaluation of improvement activities. Fig. 3 shows the measures to prevent the progressive collapse of the structure.

Cloud computing technology in the tourism industry, the largest tourism information resource saving technology, through the construction of a large "cloud pool" will be a collection of numerous tourist information on one platform, "who use pays" and make full use of idle resources. Under the premise to ensure security of information, on the one hand to maximize the tourist information resource utilization, on the other hand to facilitate the exchange between the main tourist market and resource sharing model.

RFID (Radio Frequency Identification) technology is a non-contact automatic identification technology, which can achieve a combination of electromagnetic signals in the non-contact 
transmission of information objects, RFID system usually consists of RFID tags, antennas, readers, and background processing system components. RFID systems general workflow is: a certain frequency emitted by the reader to the RF signal through the antenna, when the electronic tag reader antenna into the work area is activated, the tag information will be sent through the pre-built antenna. Fig.3 shows the schematic diagram of system components [5].

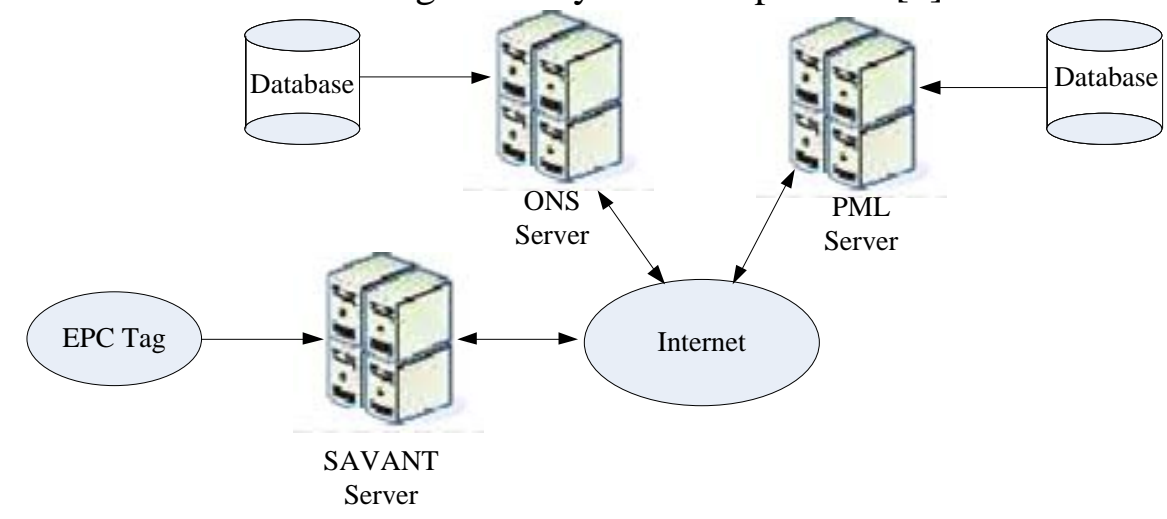

Fig. 3.The schematic diagram of system components

\section{Conclusions}

Application is the core of smart tour offers visitors an interactive experience-centric information service, travel information systems to strengthen the research has important practical significance. From the aspects of building information standardization system, we can create information service platform, attention institutional environment to optimize working to achieve homeostasis tourism information systems, thereby contributing to the sustainable development of tourism. Enhance scientific and technological content and quality tourism destination management services, providing healthy, safe and comfortable travel experience as a tourist destination. Construction smart tourist city of three core objectives are: provide more convenient for all types of tourists, intelligent travel experience; management for the industry to provide more efficient and intelligent information platform; promote deep development of tourism resources, tourism resources to further enlarge benefits. The overall architecture of the general smart tourist is constitutes of a platform, a number of support systems and the corresponding basic environment.

\section{References}

[1] Eger, John M. Smart Growth, Smart Cities, and the Crisis at the Pump a Worldwide Phenomenon. I-ways. 2009 (32).

[2] X.Y. Zhang, Haiyan Song, George Q. Huang. Tourism supply chain management: A new research agenda. Tourism Management, 2009:345-357.

[3] Liu, S. et. al., Towards mobility-based clustering, Proceedings of the 16th ACM SIGKDD International Conference on Knowledge Discovery and Data Mining, 2010, 919-928.

[4] Ulrike Gretzel. Review article intelligent system in tourism: A social science perspective. Annals of Tourism Research, 2011, 38(3): 757-779.

[5] Tsai, M., W. Lee and H. Wu. Determinants of RFID adoption intention: Evidence from Taiwanese retail chains. Information \& Management, 2010. 47(5-6): p. 255-261. 